\title{
Breast Cancer Awareness among Female School Teachers in Saudi Arabia: A Population Based Survey
}

\author{
Basem Alshareef ${ }^{1 *}$,Waed Yaseen ${ }^{1 *}$,Wed Jawa ${ }^{2}$,Yasmeen Barnawe ${ }^{3}$,Wejdan \\ Alshehry $^{4}$, Heba Alqethami ${ }^{5}$, Wala Bukari ${ }^{6}$, Osama Alqumaili ${ }^{1}$
}

\begin{abstract}
Introduction: Breast cancer (BC) is the most frequent malignancy in women and second leading cause of cancer related death worldwide. In Saudi Arabia, it is the ninth leading cause of death. Few studies have been conducted to address $\mathrm{BC}$ awareness in KSA in general and to our knowledge, this is the first to be conducted in the Makkah region. Aim: To assess the level of awareness, knowledge and attitude of Saudi female teachers towards BC, in primary intermediate and secondary schools within the Makkah region. Method and Materials: The study proposal was approved by the Research Ethical Committee in the faculty of medicine, at Umm Al-Qura University. A self-administered questionnaire on $\mathrm{BC}$ was designed and tested. The questionnaire consisted of 23 items and covered four domains (awareness about the etiology, knowledge about $\mathrm{BC}$ risk factors, symptoms, knowledge about diagnosis and treatment\& attitude toward screening). A sample of 400 female school teachers (working in primary, intermediate and secondary schools) were selected by multistage, random sampling. A selection of forty schools, with a sample of 10 teachers from each, was chosen at random in Makkah. Proper permission was obtained from the authorities. the questionnaire was filled out by each participant. The collected data was statistically analyzed using SPSS version 21 . Results: The results showed that knowledge and attitude about $\mathrm{BC}$ amongst the female teachers differed significantly by age and marital status. Those aged 46-55 ( $\mathrm{F}=8.5, \mathrm{p}>0.002)$ and those who are married $(\mathrm{F}=2.7, \mathrm{p}>0.04)$ had more knowledge about $\mathrm{BC}$ than others. The majority of respondents had a limited level of knowledge and understanding of $\mathrm{BC}$ symptoms (Table 2). However, it also showed that the teachers are very enthusiastic to learn about BC, and its prevention. Most participants $(40 / \%)$ reported that they had not performed any breast exams before. Conclusions and Recommendation: This study indicated that Saudi female teachers' level of knowledge of BC is inadequate. Introducing and developing an effective health education program in female schools within KSA is recommended.
\end{abstract}

Keywords: Breast cancer, Saudi Arabia, screening, awareness, knowledge, school teachers

Asian Pac J Cancer Prev, 21 (2), 337-342

\section{Introduction}

Brest Cancer (BC) as a multifactorial disease is the most common cancer and the second leading cause of deaths among women worldwide. The incidence of BC is rising more rapidly in the population group that used to experience low incidence of the disease and it reduces the life expectancy of the population at risk (especially those between 31 and 50) (Adebamowo and Adekunle, 1999).

Global statistics show that the annual morbidity and mortality of BC is increasing Over1.15 million women worldwide (representing $10 \%$ of all diagnosed cancers and $23 \%$ of cancers diagnosed in women) are diagnosed with $\mathrm{BC}$ each year and more than 502,000 of them die from the disease (more than $1.6 \%$ of all female mortality worldwide) (Ferlay et al., 2007).
Women in the Middle East face a significant risk of high mortality rate from $\mathrm{BC}$, due to the delay in the diagnosis and the advanced stages of the disease at the time of diagnosis (Alharbi et al., 2012; Abulkhair et al., 2010). In kingdom of Saudi Arabia, BC is usually diagnosed at late stage and more frequently in young, pre-menopausal women, under the age of 45 , in comparison to western countries (Alharbi et al., 2012; Abulkhair et al., 2010).

The etiologies of the majority of BCs are unknown, with only about $25 \%$ to $40 \%$ of them attributed to well known risk factors (ACS, 2009).

Awareness of $\mathrm{BC}$ risk factors (gender, age, family, personal history, racial factors, radiation exposure, breast changes, early menarche, late menopause, prolonged null parity, obesity, diet, alcohol consumption, tobacco smoking, excessive estrogen exposure, oral contraceptive

${ }^{1}$ Consultant General Surgery, Department of General Surgery, Alnoor Specialized Hospital, ${ }^{2}$ Department of Obstetric and Gynecology, Maternity and Children's Hospital, ${ }^{5}$ Department of General Surgery, King Faisal General Hospital, ${ }^{6}$ Department of Obstetric and Gynecology, Heraa General Hospital, Makkah, ${ }^{3}$ Resident Community Medicine, ${ }^{4}$ Department of Obstetric and Gynecology, Armed Forces Hospital, Taif, Saudi Arabia.*For Correspondence: basem@ualberta.ca,waedyaseen@hotmail.com 
use, stress, anxiety) and perception of personal risk, are important factors for motivation, prevention, and/or early detection of the disease (Bassey et al., 2010; Irurhe et al., 2011; Rojas and Stuckey, 2011). Knowledge about the disease (including screening methods and warning signs) plays an important and effective role towards developing and employing screening programs in a community. This can effectively improve the chances of early detection of $\mathrm{BC}$, should result in an improvement in survival rates and quality of life (Elmore et al., 2005).

Late diagnosis of $\mathrm{BC}$ is mainly due to lack of awareness in the population and barriers to access health services (Abulkhair et al., 2010; WHO, 2012).

Early detection of BC can be achieved through: Implementing effective screening programs and annual mammogram in the targeted population; Improving public awareness about signs and symptom of BC; and the encouragement of females to take a prompt action (Abulkhair et al., 2010; Alam, 2006; Burgess et al., 2009; Forbeslj1 et al., 2011) Unfortunately, in Saudi Arabia, we don't have a national screening program. However, there are several local/regional programs and activities such as: the public awareness of BC through lectures, in a major hospital in Riyadh (Abulkhairoa et al., 2010), a year-round, well-designed, public awareness program; and the first, organized population-based mammography screening program, in Alqassim region (Ravichandran et al., 2011).

Very little information exists on the perceptions and beliefs of females in Saudi Arabia about BC and BC control. It is well-known that to improve cancer control, it is important to understand what they know about the disease, its screening, early detection and treatment (Dandash and Al-Mohaimeed, 2007).

In KSA, studies related to knowledge, attitudes, and practices around $\mathrm{BC}$ are scarce. Madanat and Merrill (2002) found a very low level of knowledge of BC and its associated risk factors among female high-school students (Irurhe et al., 2011). However, an older female population from Riyadh, was found to be more knowledgeable about BC. Among 864 women aged 20-50, living in Riyadh, $82 \%$ knew about breast self-examination, and $61 \%$ knew about mammographies. However, only $41.2 \%$ had performed breast self-examinations, and only $18.2 \%$ had ever had a mammogram (Rojas and Stuckey, 2011). In Al Hassa governorate, a population-based study found even lower rates of mammography (5.1\% among 1,315 women aged 18-65 years old) (Elmore et al., 2005). Another study of teachers in their thirties, also showed low levels of breast-cancer-related knowledge, with only $32.4 \%$ being aware of breast self-examination (Abulkhair et al., 2010). Whether Saudi women know about BC screening and whether those above 50 years are being screened for $\mathrm{BC}$ at least once every two years is unknown. We conducted a regional survey, to investigate knowledge and practices of $\mathrm{BC}$ screening among school teachers, in order to assess the need for $\mathrm{BC}$ and cancer awareness national health programs.

Several studies have shown inadequate levels of knowledge towards risk factor awareness and cancer screening (like clinical breast examinations and mammogram), even among educated women (Amin et al., 2009).

In Saudi Arabia, a few studies have been carried out to assess awareness towards risk factors of $\mathrm{BC}$, with some methodological limitations (Alam, 2006; Bener et al., 2009). While none exist assessing the distribution of various risk factors implicated in $\mathrm{BC}$, as well as screening behavior. Consequently, the objective of this study was to assess level and determinants of knowledge about, risk factors, behaviorand utilization of screening methods used for BC.

Cost and availability of health insurance have been found to act as barriers to BC screening in the U.S. and other parts of the world, but not in Saudi Arabia, where a mammography is usually either free or covered by insurance (Milaat, 2000; Bener et al., 2009).

We aim in this study to assess knowledge, awareness, attitude and practice of Saudi females towards BC and screening for BC. We picked school teachers as our sample, because they constitute a large number of the population; thus the result of the study, we believe, can be applied to the whole population of Saudi Arabia.

Also, school teachers are classified as a 'well-educated' sector in the country and it is expected that they are well aware of and oriented about BC.

Finally, we couldn't find any similar study done in the Makkah region and we hope that with this study we can attract some attention, to develop awareness and screening programs for $\mathrm{BC}$ here.

\section{Materials and Methods}

\section{Study Design \\ Cross-sectional survey in the city of Makkah}

Study Population and sample size: A total sample of 400 school teachers working in primary, intermediate and secondary schools, were selected by multistage random sampling. Forty schools in the city of Makkah were selected randomly, and a sample of 10 teachers were randomly selected from each school. Sample size was determined using sample size determination tables, as according to the ministry of education's website, the total number of teachers is 12905 and the sample size is 365 . However, considering $10 \%$ non response rate the final sample size is 400 .

\section{Instruments}

A questionnaire was developed based on a comprehensive review of literature, to include questions on women's awareness level about different aspects of BC. The original questionnaire was in English, for which translation into Arabic, with back translation to English was done, to preserve the original construct. Content validity was reviewed by 2 experts in the field. There were twenty-three questions covering the important aspects of $\mathrm{BC}$ that the public should know, including: risk factors, signs, screening, treatment methods, screening centers in Makkah and the information sources for each. Questions assessing knowledge score were given a value of one if correct and zero if incorrect. The total knowledge score 
was 37.

Data collectors were recruitedand trained for 2 days. In the training session, the data collectors were oriented about the subject itself; we give them a workshop to explain objectives of the study anddata collection process. All collected data was reviewed by the supervisors and principle investigators.

Initially, we did a pilot study on 10 school teachers to ensure quality, clarity and completeness of data.

\section{Statistical Analysis}

Data was analyzed using SPSS software, version 21. Scores of knowledge items were summed to obtain the mean total knowledge score on $\mathrm{BC}$, total scores were found to be normally distributed. Descriptive tests (frequency, mean, standard deviation (SD) and percentages) were done to characterize different variables. Parametric tests (T-test and ANOVA test) were applied to compare knowledge across the socio-demographic variables. Multiple linear regression analysis was performed to obtain the significant predictors of $\mathrm{BC}$ knowledge. The level of significance was set below $5 \%(p<0.05)$.

\section{Ethical Consideration}

Participants were informed about the nature of the study. Written consent was obtained. All information obtained from participants was anonymous. Approval from the Research Ethical Committee in the faculty of medicine at Umm Al-Qura University was obtained and the study was conducted after approval.

\section{Results}

The response rate was $100 \%$ as all participants responded to the questionnaire; the majority of the respondents were between 36 and 45 years old (49\%), married (70\%) and held a bachelors degree (77\%). Seventy eight percent of them didn't have a family history of BCand $81 \%$ haven't had any breast disease before Table 1 .

Table 2 Illustrates respondents knowledge about risk factors and warning signs. Alcohol was the most identified risk factor $(82 \%)$, followed by family history $(69 \%)$ andlong term oral contraceptive pill use (66\%). Increased maternal age at first pregnancy $(0.9 \%)$ was the least identified risk factor, followed by late menopause (hormonal therapy exposure) $(3 \%)$ and early menarche $(5 \%)$. The majority of respondents identified a lump under the armpit (75\%) as a $\mathrm{BC}$ warning sign, followed by a painless breast lump (65\%) and bleeding or discharges from the nipple (52\%). Weight loss $(22 \%)$ and nipple pain $(35 \%)$ were the least identified warning signs of BC.

Respondents' mean scores of their overall knowledge about BC based on some demographical characteristics: It is found that the overall mean score for the participants' knowledge levels about BC is $15.6 \pm 4.19$. Most participants' $(67 \%)$ had a weak knowledge score, followed by an average knowledge score of (24\%).the lowest percentage of participants' $(6 \%)$ had a good knowledge score.

School teachers' knowledge about BC differed significantly by their age and marital status, as those aged
Table 1. Socio-Demographic Characteristics of the Respondents $(n=400)$

\begin{tabular}{|c|c|c|}
\hline Characteristic & $\mathrm{N}$ & $\%$ \\
\hline \multicolumn{3}{|l|}{ Age } \\
\hline $25-35$ & 145 & 36.3 \\
\hline $36-45$ & 197 & 49.3 \\
\hline $46-55$ & 58 & 14.5 \\
\hline \multicolumn{3}{|l|}{ Marital Status } \\
\hline Single & 71 & 17.8 \\
\hline Married & 282 & 70.5 \\
\hline Divorced & 32 & 8 \\
\hline Widowed & 15 & 3.8 \\
\hline \multicolumn{3}{|l|}{ Educational Level } \\
\hline Diploma & 66 & 16.5 \\
\hline Bachelor & 311 & 77.8 \\
\hline Master & 15 & 3.8 \\
\hline Doctorate & 2 & 0.5 \\
\hline Others & 6 & 1.5 \\
\hline \multicolumn{3}{|l|}{ Family History of Breast Cancer } \\
\hline Yes & 63 & 15.8 \\
\hline No & 314 & 78.5 \\
\hline I don't know & 23 & 5.8 \\
\hline \multicolumn{3}{|l|}{ *Who Had Breast Cancer In Family } \\
\hline Mother & 21 & 33.3 \\
\hline Sister & 5 & 7.9 \\
\hline Ant & 14 & 22.2 \\
\hline Grandmother & 5 & 7.9 \\
\hline Others & 18 & 28.6 \\
\hline \multicolumn{3}{|l|}{ Had Breast Disease } \\
\hline No & 227 & 81.5 \\
\hline breast inflammation & 15 & 3.7 \\
\hline breast ulcer & 3 & 0.7 \\
\hline breast tumor & 4 & 1 \\
\hline nipple secretions & 23 & 5.7 \\
\hline breast lump & 27 & 6.7 \\
\hline other breast problem & 2 & 0.5 \\
\hline Have you ever had a mammogram? & 51 & 12.8 \\
\hline Yes & 51 & 12.8 \\
\hline \multicolumn{3}{|l|}{ If yes why? } \\
\hline For Screening & 36 & $70.59 *$ \\
\hline For Diagnosis & 15 & $29.41 *$ \\
\hline \multicolumn{3}{|c|}{ have you ever done breast self-examination? } \\
\hline Yes & 169 & 42.3 \\
\hline \multicolumn{3}{|l|}{ if no why? } \\
\hline I did not know it excited & 37 & 15.7 \\
\hline I don't know how to do it & 120 & 50.8 \\
\hline I don't think it's important & 14 & 5.9 \\
\hline I don't think I need it & 65 & 27.5 \\
\hline
\end{tabular}

*For participants' who answered Yes $(n=63)$. 
Table 2. Respondents Knowledge about Risk Factors and Warning Signs of Breast Cancer

\begin{tabular}{lcc}
\hline Item & \multicolumn{2}{c}{ True } \\
& $\mathrm{n}$ & $\%$ \\
\hline Risk Factors: & & \\
Family History & 278 & 69.50 \\
Early menarche & 23 & 5.80 \\
Old age of first pregnancy & 25 & 0.90 \\
Early menopause & 101 & 25.30 \\
Aging & 104 & 26.00 \\
Increase maternal age at first pregnancy & 25 & 6.30 \\
Early menopause & 101 & 3.70 \\
Number of pregnancies' & 84 & 21.00 \\
Infertility & 68 & 17.00 \\
Staying Single & 46 & 11.50 \\
Obesity & 113 & 28.30 \\
Fatty foods & 134 & 33.50 \\
OCP use & 265 & 66.30 \\
Increased Stress Levels & 275 & 68.80 \\
X-ray Exposure & 315 & 78.80 \\
Smoking & 251 & 62.80 \\
Alcohol drink & 331 & 82.80 \\
Worming Sings: & & \\
Painless Breast Lump & 261 & 65.40 \\
Changes in the size of breast or nipple & 192 & 48.10 \\
Changes in the shape of breast or nipple & 203 & 50.90 \\
Bleeding or discharge from the nipple & 210 & 52.60 \\
Pulling of the nipple & 168 & 42.10 \\
nipple pain & 142 & 35.60 \\
Wight loss & 88 & 22.10 \\
Redness of the breast skin & 42.90 \\
Lump under armpit & & \\
\hline & & \\
& & \\
& &
\end{tabular}

46-55 $(\mathrm{F}=8.5, \mathrm{p}>0.00)$ and those who are married $(\mathrm{F}=2.7$, $\mathrm{p}>0.04$ ) had more knowledge about BC than others .

Table 3,4, Univariate linear regression analysis was done to the age, marital status, education level, those with family history of BCand those who had breast disease. Multi-collinearity was checked and the analysis showed no intercorrelation among the independent variables. Only age was statistically significant $(\mathrm{P}<0.05)$.

Table 5, Forty five percent of participants' knew about BC Screening centers in Makkah city, 93.3\% of respondents think that early $\mathrm{BC}$ screening is important, $92.3 \%$ stated that they would go to see a doctor only if they had breast problem and over half of the participants would agree to participate in a BC screening program.

Fifty-one participants had undergone a mammography and only 31 out of them were for screening. Out of all participants, $57 \%$ thought that $\mathrm{BC}$ treatment depends on the stage (Table7).

\section{Discussion}

In Saudi Arabia, BC is the most common cancer among females. It usually presents at advanced stages andit is considered the leading cause of cancer mortality in women (14\% of female cancer deaths). Since it is known that education and awareness lead to better screening and subsequently early detection (which contribute to better treatment and prognosis), we designed this study toinvestigate the level of $\mathrm{BC}$ awareness among Saudi female's teachers in Makkah. As we can see, only $3.8 \%$ know what a mammogram is and only $8 \%$ know that it should be started at the age of 50 . These results, unfortunately, reflect the poor knowledge of the study group and when we looked at the literature, there was no similar study which asked the same questions. When it comes to the treatment options, we also found that there is relatively poor knowledge about choices of treatment for breast cancer ( $57 \%$ know that it depends on the stage).

Our findings show that the overall mean score for the participants' information levels about breast cancer is 15.6 \pm 4.19. Most of the participants' $(67 \%)$ had a weak knowledge score of $49-25 \%$, four percent had an average knowledge score of 50-74\%, and the lowest percentage of participants' $(6 \%)$ had a good knowledge score of $\geq 75 \%$.

Regarding the screening methods: $50 \%$ of our sample had a weak knowledge and $1.5 \%$ had a good score.

This finding also supports previous study by Alam et al11 (2006); she reported smoking, hormone replacement therapy and exposure to excess radiation as common BC risk factors noted by women in Riyadh.

Regarding women's' awareness of BC warning signs; painless breast lump was the most frequently identified symptom $(65 \%)$, followed by bleeding or nipple discharge

Table 3. Participants' Knowledge Score Toward BC

\begin{tabular}{lcccccc}
\hline & \multicolumn{2}{c}{$\begin{array}{c}\text { Disease knowledge } \\
\text { score }=30\end{array}$} & \multicolumn{2}{c}{$\begin{array}{c}\text { Screening knowledge } \\
\text { score }=7\end{array}$} & \multicolumn{2}{c}{$\begin{array}{c}\text { Overall knowledge } \\
\text { score }=37\end{array}$} \\
& $\mathrm{~N}$ & $\%$ & $\mathrm{~N}$ & $\%$ & $\mathrm{~N}$ & $\%$ \\
\hline Weak* & 246 & 61.5 & 202 & 50.5 & 271 & 67.75 \\
Average* & 99 & 24.7 & 182 & 45.5 & 96 & 24 \\
Good* & 6 & 1.5 & 6 & 1.5 & 6 & 1.5 \\
Range & $3-24$ & & $3-6$ & & $6-29$ & $15.6 \pm 4.19$ \\
Mean \pm SD & $12.27 \pm 3.93$ & & $3,33 \pm 1.11$ & & 205.11 \\
Chi-square & $\mathrm{X}^{2}$ & 286.8 & 197.6 & & $<0.001$ \\
& $\mathrm{P}$ & $<0.001$ & $<0.001$ & & \\
\hline
\end{tabular}

*Weak, (score 49-25\%); Average, (score 50-74\%); Good, ( score $\leq 75 \%$ ) 
Table 4. Differences in Respondents Breast Cancer Knowledge by Demographic Variables

\begin{tabular}{|c|c|c|c|c|}
\hline Characteristic & Mean & SD & $\mathrm{F}$ & P-Value \\
\hline \multicolumn{5}{|l|}{ Age } \\
\hline $25-35$ & 17.62 & 3.608 & 8.516 & 0 \\
\hline $36-45$ & 18.81 & 3.902 & & \\
\hline $46-55$ & 19.98 & 4.47 & & \\
\hline \multicolumn{5}{|l|}{ Marital Status } \\
\hline Single & 17.46 & 3.66 & 2.78 & 0.041 \\
\hline Married & 18.89 & 4.044 & & \\
\hline Divorced & 17.94 & 3.991 & & \\
\hline Widowed & 18.47 & 2.669 & & \\
\hline \multicolumn{5}{|c|}{ Educational Level } \\
\hline Diploma & 19.05 & 4.145 & 0.721 & 0.578 \\
\hline Bachelor & 18.42 & 3.938 & & \\
\hline Master & 18.4 & 3.699 & & \\
\hline Doctorate & 22 & 7.071 & & \\
\hline Others & 18.67 & 2.944 & & \\
\hline \multicolumn{5}{|c|}{ Family History of Breast Cancer } \\
\hline Yes & 18.73 & 4.064 & 1.545 & 0.215 \\
\hline No & 17.87 & 3.348 & & \\
\hline I don't know & 17.91 & 3.942 & & \\
\hline \multicolumn{5}{|c|}{ Had Breast Disease } \\
\hline Yes & 18.48 & 3.969 & $-0.162 *$ & $-0.083^{*}$ \\
\hline No & 18.56 & 3.963 & & \\
\hline \multicolumn{5}{|c|}{ Practice Breast Self Examination } \\
\hline Yes & 19.07 & 4.121 & $2.32 *$ & $0.021 *$ \\
\hline No & 18.13 & 3.756 & & \\
\hline \multicolumn{5}{|c|}{ Had Mammography } \\
\hline Yes & 19.65 & 5.047 & $2.193^{*}$ & $0.085^{*}$ \\
\hline No & 18.36 & 3.726 & & \\
\hline
\end{tabular}

(52\%) and change in the shape of breast or nipple (50\%). Knowledge of other warning signs were limited, as only few females knew that weight loss $(22 \%)$ and nipple pain (35\%) are warning signs of Radi et al., (2013) reported similar findings in their study.

This finding is in agreement with what has been reported by Parsa et al., (2008) in their studythey reported that the majority of participants had a low level of knowledge (63\%).

Table 5. Predictors of Breast Cancer Knowledge by Univariat Linear Regression $(\mathrm{n}=400)$

\begin{tabular}{|c|c|c|c|c|c|c|}
\hline & \multirow[t]{2}{*}{ B } & \multirow[t]{2}{*}{ SE } & \multirow[t]{2}{*}{ Beta } & \multirow{2}{*}{$\begin{array}{c}\mathrm{P} \\
\text { value }\end{array}$} & \multicolumn{2}{|c|}{$95 \% \mathrm{CI}$} \\
\hline & & & & & Lower & Upper \\
\hline Age & 1.182 & 0.286 & 0.203 & 0 & 0.62 & 1.745 \\
\hline Marital Status & 0.337 & 0.31 & 0.054 & 0.277 & -0.273 & 0.947 \\
\hline $\begin{array}{l}\text { Educational } \\
\text { Level }\end{array}$ & -0.136 & 0.334 & -0.020 & 0.685 & -0.792 & 0.521 \\
\hline Family History & -0.572 & 0.353 & -0.081 & 0.106 & -1.26 & 0.122 \\
\hline $\begin{array}{l}\text { Had Breast } \\
\text { Disease }\end{array}$ & -0.083 & 0.513 & -0.008 & 0.871 & -1.09 & 0.926 \\
\hline
\end{tabular}

Table 6. Participants' Attitude Toward Screening Programs

\begin{tabular}{lcc}
\hline Question & $\mathrm{n}$ & $\%$ \\
\hline $\begin{array}{l}\text { do you know any breast cancer screening } \\
\text { center in Makkah? }\end{array}$ & 181 & 45.3 \\
$\begin{array}{l}\text { do you think early breast cancer screening is } \\
\text { important? }\end{array}$ & 385 & 96.3 \\
$\begin{array}{l}\text { Would you agree to participate in a Breast } \\
\text { Cancer screening Program If offered? }\end{array}$ & 237 & 59.3 \\
$\begin{array}{l}\text { if you or a family member had any breast } \\
\text { problem would you go to the doctor? }\end{array}$ & 369 & 92.3 \\
$\begin{array}{l}\text { have you ever had a breast cancer examination } \\
\text { by a doctor? }\end{array}$ & 107 & 26.8 \\
\hline
\end{tabular}

Table 7. Participants' Knowledge About Breast Cancer Screening and Treatment

\begin{tabular}{|c|c|c|}
\hline Question & $\mathrm{n}^{*}$ & $\% *$ \\
\hline $\begin{array}{l}\text { What percentage do you think the risk of breast } \\
\text { cancer in women? }(<25 \%)\end{array}$ & 155 & 38.8 \\
\hline What is mammogram? (breast $\mathrm{x}$-ray) & 33 & 3.8 \\
\hline $\begin{array}{l}\text { How often should mammogram be done? } \\
\text { (annually) }\end{array}$ & 93 & 23.3 \\
\hline $\begin{array}{l}\text { At what age do you think mammogram screening } \\
\text { should start? }(50)\end{array}$ & 32 & 8 \\
\hline Have you ever had a mammogram? (yes) & 51 & 12.8 \\
\hline \multicolumn{3}{|l|}{ If yes why? } \\
\hline For Screening & 36 & $70.59 *$ \\
\hline For Diagnosis & 15 & $29.41 *$ \\
\hline have you ever done breast self-examination? (yes) & 169 & 42.3 \\
\hline \multicolumn{3}{|l|}{ if no why? } \\
\hline I did not know it excited & 37 & 15.7 \\
\hline I don't know how to do it & 120 & 50.8 \\
\hline I don't think it's important & 14 & 5.9 \\
\hline I don't think I need it & 65 & 27.5 \\
\hline \multicolumn{3}{|l|}{ What is the treatment of breast cancer? } \\
\hline Chemotherapy and radiotherapy & 69 & 17.3 \\
\hline Hormonal therapy & 16 & 4 \\
\hline Surgery or removal of the whole breast & 84 & 21 \\
\hline It depends the stage & 231 & 57.7 \\
\hline
\end{tabular}

When we compared the demographic variables of our population, we noted that marital status and age affected awareness level significantly; as older married females had learned more about the disease and were more aware about screening methods. However, we found that educational level didn't affect awareness about BC, as more educated females didn't necessarily know more about the disease or its screening.

The results were consistent with the literature, as published by Dandash and Al-Mohaimeed (2007), and Milaat (2000) on the other hand, these studies showed the significant effect of education on awareness levels, unlike our study, which showed no difference. We think that discrepancy is related to the study group itself. In the last part of the study, we measured the response to screening programs in the literature Radi et al which reported better 
knowledge in Jeddah city, which is not far from Makkah and has almost similar population demography. We think this difference is mainly due to the society and awareness campaigning, which is usually in Jeddah city.

In conclusions, Brest Cancer is the most common cancer and the second leading cause of deaths among women worldwide. Unfortunately, there is huge defect in the awareness among females in Makkah and in the country in general.

\section{Acknowledgements}

\section{Recommendation}

To improve knowledge about breast cancer and change the misconceptions, we need to achieve better awareness through:

- Health educational programs

- Counseling should be provided for women by healthcare professionals, especially the primary health care providers

- Cooperative efforts between the ministry of health and mass media, to enhance the awareness about breast cancer screening practices.

\section{References}

Abulkhair O, Al Tahan F, Young S, Musaad S, Jazieha D (2010). The first national public BC screening program in Saudi Arabia. Ann Saudi Med, 30, 350-7.

Abulkhair OA, Al Tahan FM, Young SE, Musaad SM, Jazieh AR (2010). The first national public BC screening program in Saudi Arabia. Ann Saudi Med, 30, 350-7

Adebamowo CA, Adekunle OO (1999). Case controlled study of the epidemiology risk factors for $\mathrm{BC}$ in Nigeria. $\mathrm{Br} J$ Surg, 86, 665-8.

Alam A (2006). Knowledge of BCand its risk andprotective factors among women in Riyadh. Ann Saudi Med, 26, 272-7.

Alharbi N, Alshammari M, Almutairi B, Makboul G, El-Shazlym F (2012). Knowledge, awareness, and practices concerningBC among Kuwaiti female school teachers. AJM, 82, 75-84.

American cancer society (2009), BC facts and figures 2009-2010, American cancer society, Atlanta, Ga, USA.

Amin TT, Al Mulhim ARS, Al Meqihwi A (2009). Breast cancer knowledge, risk factors and screening among adult Saudi women in a primary health care setting. Asian Pac J Cancer Prev, 10, 133-8.

Bassey RB, Irurhe NK, Olowoyeye OA, Adeyomoye AA, Onajole AT (2010). Knowledge, attitude and practice of breast self-examination among nursing students in Lagos university teaching hospital. Acad J Cancer Res, 3, 11-5.

Bener A, El Ayoubi HR, Moore A, et al (2009). Do we need to maximize the breast cancer screening awareness?: Experience with an Endogamous Society with high fertility. Asian Pac J Cancer Prev, 10, 599-604.

Burgess CC, Linsell L, Kapari M, et al (2009). Promoting early presentation of $\mathrm{BC}$ by older women: a preliminary evaluation of a one-to-one health professional-delivered intervention. $J$ Psychosomatic Res, 67, 377-87

Dandash KF, Al-Mohaimeed A (2007) Knowledge, attitudes, and practices surrounding breast cancer and screening in female teachers of Buraidah, Saudi Arabia. Int J Health Sci, 1, 61-71.

Elmore JG, Armstrong K, Lehman CD, Fletcher SW (2005). Screening for BC. JAMA, 293, 1245-56.
Ferlay J, Bray F, Pisani P, Parkin D, Globocan 2002 (2004). Cancer incidence, mortality and prevalence worldwide, Iarc cancer base no. 5, version 2.0, Iarc press, Lyon, France, 2004, Valero-malaria in Colombia, 2007.

ForbesljL, Linsell L, Atkins L, et al (2011). Promoting early presentation intervention increases $\mathrm{BC}$ awareness in older women after 2 years: a randomised controlled trial. $\mathrm{Br} \mathrm{J}$ Cancer, 105, 18.

Irurhe NK, Olowoyeye OA, Arogundade RA, Bassey RB, Onajole AT (2011). Knowledge, attitude and practice of breast self-examination among female medical students in University of Lagos. Internet J Health, 12, 1-12

Madanat H, Merrill RM (2002). Breast cancer risk-factor and screening awareness among women nurses and teachers in Amman, Jordan. Cancer Nurs, 25, 276e82.

Milaat WA (2000) Knowledge of secondary-school female students on breast cancer and breast self examination in Jeddah, Saudi Arabia. East Mediterr Health J, 6, 338-44.

Montazeri A, Vahdaninia M, Harirchi I, et al (2008). BC in Iran: need for greater women awareness of warning signs and effective screening methods. Asia Pac Fam Med, 7, No. 1 , article 6.

Parsa P, Kandiah M, Mohd Zulkefli NA, Rahman HA (2008). Knowledge and behavior regarding breast cancer screening among female teachers in Selangor, Malaysia. Asian Pac J Cancer Prev, 9, 221-7.

Radi, S. M. (2013). Breast cancer awareness among Saudi females in Jeddah. Asian Pac J Cancer Prev, 14, 4307-12.

Ravichandran K, Al-Hamdan NA, Mohamed G (2011). Knowledge, attitude, and behavior among Saudis toward cancer preventive practice. J Community Fam Med, 18, 135 .

Rojas K, Stuckey A (2011). Breast cancer epidemiology and risk factors. Clin Obstet Gynecol, 59, 651-72.

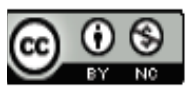

This work is licensed under a Creative Commons AttributionNon Commercial 4.0 International License. 